\title{
Management of patients with type 2 diabetes and mild/moderate renal impairment: profile of linagliptin
}

This article was published in the following Dove Press journal:

Therapeutics and Clinical Risk Management

14 May 2015

Number of times this article has been viewed

\section{Baptist Gallwitz}

Department of Medicine IV, EberhardKarls University, Tübingen, Germany
Correspondence: Baptist Gallwitz Department of Medicine IV, EberhardKarls University, Otfried-Müller-Str 10, 72076 Tübingen, Germany

Tel +49 707I 2982093

Fax +40 707I 295004

Email baptist.gallwitz@med.unituebingen.de
Abstract: Dipeptidyl-peptidase-IV (DPP-4) inhibitors are oral antidiabetic agents that can be administered as monotherapy in patients with contraindications to metformin or metformin intolerance, and in combination with other oral compounds and/or insulin. DPP-4 inhibitors act in a glucose-dependent manner and only increase insulin secretion and inhibit glucagon secretion under hyperglycemic conditions. Renal impairment is frequent in type 2 diabetes as a result of microvascular complications and diabetes treatment, and options in these patients are limited. Linagliptin is a DPP-4 inhibitor with a hepatobiliary route of elimination. In comparative studies, it was noninferior to metformin and sulfonylureas in lowering glycated hemoglobin $\left(\mathrm{HbA}_{1 \mathrm{c}}\right)$ and improving glycemic parameters. It can be used throughout all stages of renal impairment without dose adjustments. This review gives an overview of linagliptin in various stages of chronic kidney disease and has a focus on efficacy and safety parameters from clinical studies in patients with impaired renal function. These data are interpreted in the context of type 2 diabetes therapy in general.

Keywords: type 2 diabetes, renal impairment, oral antidiabetic drugs, incretin based therapies, DPP-4 inhibitors, linagliptin

\section{Introduction}

Renal impairment and chronic kidney disease (CKD) are a common consequence of microvascular complications in patients with type 2 diabetes. This phenomenon is associated with increasing diabetes duration and insufficient glycemic control. ${ }^{1}$ An improvement of $\mathrm{HbA}_{1 \mathrm{c}}$ can significantly prevent or slow down the rate of progression of microvascular complications., ${ }^{2,3}$ However, the classic oral antidiabetic agents can only be used with caution or are contraindicated in CKD. Metformin is contraindicated in moderate and severe renal impairment due to a higher risk for lactic acidosis with metformin accumulation. ${ }^{4}$ Sulfonylureas as compound class with a predominantly renal elimination have restrictions for their use in CKD as well. ${ }^{5}$

Dipeptidyl-peptidase-IV (DPP-4) inhibitors became part of the therapeutic options for type 2 diabetes approximately 10 years ago. They increase the plasma- and local concentrations of DPP-4, the enzyme that degrades and inactivates the incretin hormones glucagon-like peptide-1 (GLP-1) and glucose-dependent insulin tropic peptide (GIP). ${ }^{6,7}$ These peptide hormones stimulate postprandial insulin secretion in a strictly glucose-dependent manner only under hyperglycemic conditions. ${ }^{8}$ GLP-1 also inhibits glucagon secretion in a glucose-dependent fashion. ${ }^{9}$ The DPP-4 inhibitors therefore have a very low intrinsic risk for hypoglycemia. In clinical studies, they demonstrated a comparable efficacy on $\mathrm{HbA}_{1 \mathrm{c}}$ and other glycemic parameters to metformin or sulfonylureas. ${ }^{10}$ The hypoglycemia incidence was significantly lower 
in patients treated with DPP-4 inhibitors compared to those with sulfonylureas and besides that DPP-4 inhibitors proved to be body weight neutral. ${ }^{11-14}$ Most guidelines as well as the recommendations of the American Diabetes Association (ADA) and European Association for the Study of Diabetes (EASD) have placed DPP-4 inhibitors as second-line therapy when metformin monotherapy is not sufficient any longer. They are also indicated for monotherapy or combination therapy with other drugs when metformin is not tolerated or contraindicated. ${ }^{15}$

Linagliptin belongs to the xanthine-based DPP-4 inhibitors. It is characterized by hepatobiliary elimination, while most other DPP-4 inhibitors that are available today with the exception of teneligliptin (that is also eliminated with the feces) are excreted mostly via a renal route. ${ }^{16}$ Linagliptin can therefore be used in a whole spectrum of renal function including CKD to stage 5 (glomerular filtration rate $<15 \mathrm{~mL}$ / $\min / 1.73 \mathrm{~m}^{2}$ ) without the necessity to perform dose adjustments. Like other DPP-4 inhibitors, linagliptin is contraindicated for use in type 1 diabetes and in diabetic ketoacidosis as well as in pregnancy. The side-effect profile of linagliptin is also similar to that of other DPP-4 inhibitors with respiratory side effects (nasopharyngitis, upper respiratory tract infection, and cough), dermatological side effects (urticaria and skin rashes) as well as back pain being the most frequently reported side effects in the $1 \%$ to maximally $10 \%$ range. In clinical studies, linagliptin was also noninferior to metformin and sulfonylureas regarding its effect on glycemic parameters and comparable to other DPP-4 inhibitors. The safety profile was more favorable than that of a sulfonylurea with respect to hypoglycemia and body weight gain. A composite endpoint (consisting of a combination of $\mathrm{HbA}_{1 \mathrm{c}}<7 \%$ without hypoglycemia and without weight gain) was achieved more frequently in patients treated with linagliptin compared to patients treated with the sulfonylurea glimepiride. Linagliptin had a better safety profile regarding a combined cardiovascular endpoint, including stroke. An explanation for this finding is a higher incidence of hypoglycemia under glimepiride therapy and the sulfonylurea titration. ${ }^{14}$

This review gives a summary and perspective on the efficacy, characteristics, and safety of linagliptin in treating type 2 diabetes patients with renal impairment.

\section{Chemical characteristics and pharmacology of linagliptin}

Linagliptin was developed by Boehringer Ingelheim Pharmaceuticals (Ingelheim, Germany). The molecule has a xanthine-based structure. The DPP-4 inhibition is competitive and reversible. Linagliptin dissociates slowly from the active center of the enzyme DPP-4 after binding. ${ }^{17}$ The selectivity is approximately 40,000-fold higher toward DPP-4 in comparison to other enzymes of the DPP peptidase family. Enzymes of the cytochrome P450 (CYP450) class are not inhibited by linagliptin. ${ }^{18,19}$

Linagliptin binding to plasma proteins is almost complete at therapeutic concentrations. ${ }^{20}$ After once daily administration, steady-state concentrations are achieved after 2-5 days. A standard dose of $5 \mathrm{mg}$ linagliptin given once daily inhibits DPP-4 up to $90 \%$. This inhibition is long-lasting with $85 \%$ inhibition still present after 24 hours. ${ }^{21}$ There are no safety-relevant drug-drug interactions between other commonly used medications and linagliptin. ${ }^{22}$ The excretion and elimination of linagliptin occurs by approximately $90 \%$ unmetabolized via hepatobiliary excretion with the feces. The small portion of only $1 \%-6 \%$ is removed via renal elimination..$^{20,21,23}$

The high and low plasma concentration characteristics and pharmacokinetics of linagliptin in patients with different severities of renal impairment and CKD were investigated in several clinical studies. Most data were collected from the phase III clinical study program. This program included 969 patients who were characterized concerning their renal function by calculating the estimated glomerular filtration rate (eGFR) and 438 of these patients were detected to have normal renal function. A total of 429 participants had renal impairment CKD stage 2, 44 were characterized by CKD stage 3 , and 58 by CKD stage 4 . In subjects without renal impairment, the linagliptin trough concentration was $5.93 \mathrm{nmol} / \mathrm{L}$; in patients with CKD at stages 2, 3, or 4, the respective concentrations were $6.07 \mathrm{nmol} / \mathrm{L}, 7.34 \mathrm{nmol} / \mathrm{L}$, and $8.13 \mathrm{nmol} / \mathrm{L}$. Renal impairment did not change exposure to linagliptin significantly in patients with type 2 diabetes. Dose adjustments of linagliptin or the determination of the eGFR for calculating drug accumulation are therefore not necessary in patients with CKD. ${ }^{24,25}$

\section{Efficacy and safety of linagliptin in clinical studies}

GLP-1 serum levels increased fourfold after-meal tests in obese type 2 diabetes patients on linagliptin treatment with a moderately elevated baseline $\mathrm{HbA}_{1 \mathrm{c}}$ between $6.8 \%$ and $7.3 \%{ }^{26}$ In a dose-dependency study, the $\mathrm{HbA}_{1 \mathrm{c}}$ reductions amounted to $-0.31 \%,-0.37 \%$, and $-0.28 \%$ for the linagliptin doses of $2.5 \mathrm{mg}, 5 \mathrm{mg}$, and $10 \mathrm{mg}$, respectively. ${ }^{26}$

In drug-naive patients or after a 6-week washout from previous oral antidiabetic medication, $5 \mathrm{mg}$ linagliptin given 
once daily resulted in a significant $\mathrm{HbA}_{1 \mathrm{c}}$ drop of $-0.69 \%$ (placebo corrected) after 24 weeks. Patients with a higher baseline $\mathrm{HbA}_{1 \mathrm{c}}>9 \%$ demonstrated a larger decrease in $\mathrm{HbA}_{1 \mathrm{c}}$ $(-1.01 \%, P<0.0001) .{ }^{27}$ The hypoglycemia incidence in this study as well as a study in Japanese patients with two doses of linagliptin (5 mg and $10 \mathrm{mg}$ ) was very low and comparable to that in the placebo- or comparator arm with an $\alpha$-glucosidase inhibitor in the Japanese study. ${ }^{28}$

As an add-on to a metformin monotherapy, linagliptin at a dose of $5 \mathrm{mg}$ /day reduced the $\mathrm{HbA}_{1 \mathrm{c}}$ by $-0.49 \%$ significantly from a baseline of $8.1 \%$ compared to placebo after 24 weeks. The incidence of hypoglycemia was $0.6 \%$ with linagliptin and $2.8 \%$ in the placebo-treated group of the study. The body weight did show significant changes in this study in both the treatment groups. ${ }^{29}$

A triple therapy with linagliptin as an additional antidiabetic medication to metformin combined with sulfonylurea in an already existing combination, a significant reduction of $\mathrm{HbA}_{1 \mathrm{c}}$ by $-0.62 \%$ was observed. Symptomatic hypoglycemia was reported in $16.7 \%$ of patients on linagliptin and in $10.3 \%$ of patients treated with placebo as add-on to the metforminsulfonylurea combination. Severe hypoglycemia occurred in $2.7 \%$ of the linagliptin and $4.8 \%$ of placebo-treated study participants, respectively. Linagliptin was weight neutral as in other studies. ${ }^{30}$

The efficacy and safety of linagliptin as an add-on medication to an existing therapy with metformin were compared to glimepiride as add-on medication in a 104-week clinical study. Patients failing on metformin monotherapy and with an average baseline $\mathrm{HbA}_{1 \mathrm{c}}$ of $7.7 \%$ additionally received either a standard dose of $5 \mathrm{mg}$ linagliptin once daily or glimepiride. The average glimepiride dose was $2.45 \mathrm{mg} /$ day at the end of the study. Both study arms included approximately 750 patients. Regarding the $\mathrm{HbA}_{1 \mathrm{c}}$ reduction, linagliptin was noninferior to glimepiride. The difference in $\mathrm{HbA}_{1 \mathrm{c}}$ amounted to $0.20 \%$ (97.5\% confidence interval: $0.09-0.30)$. Linagliptin was associated with a significantly lower incidence of hypoglycemia compared to glimepiride $(7.5 \%$ vs $36.1 \%, P<0.0001$ ), and the incidence of severe hypoglycemic episodes was significantly lower in the linagliptin group (1 episode $[<1 \%]$ ) compared to glimepiride-treated patients (12 episodes [2\%]). The body weight difference amounted to $-2.7 \mathrm{~kg}(P<0.0001)$, with a small weight loss observed with linagliptin and a weight gain with glimepiride. With linagliptin, a significantly lower incidence of cardiovascular events was seen during the 2-year study. In total, 12 patients with linagliptin therapy compared to 26 patients with glimepiride had a cardiovascular event, corresponding to a relative risk of 0.46 (95\% confidence interval: $0.23-0.91, P=0.0213) .{ }^{14}$ Regarding an additional analysis of the hypoglycemic events in this study, hypoglycemic episodes were more frequent in patients on glimepiride compared to linagliptin treatment independent from baseline $\mathrm{HbA}_{1 \mathrm{c}}(P<0.0001)$, and the incidence was not associated with greater $\mathrm{HbA}_{1 \mathrm{c}}$ reductions. Therefore, linagliptin treatment demonstrated a lower hypoglycemia risk compared to glimepiride therapy regardless of the doses used and independent form the duration of treatment and the drop in $\mathrm{HbA}_{1 \mathrm{c}}{ }^{31}$ In this study, significantly more patients receiving linagliptin achieved a composite endpoint of an $\mathrm{HbA}_{1 \mathrm{c}}<7 \%$ without hypoglycemia and without body weight gain after 2 years compared with those receiving glimepiride (54\% and $23 \%$, respectively; odds ratio $3.9,95 \%$ confidence interval 2.6-5.7, $P<0.0001){ }^{32}$

Several studies investigated the initial combination of an oral antidiabetic therapy with linagliptin and other agents. All these studies demonstrated that an initial combination containing linagliptin as one component besides metformin or pioglitazone was more effective than an antidiabetic monotherapy. The combination therapies were well tolerated and did not increase the risk of hypoglycemia. In a study with patients characterized by a baseline $\mathrm{HbA}_{1 \mathrm{c}}$ of $9.8 \%$, treatment response of $\mathrm{HbA}_{1 \mathrm{c}}<7.0 \%$ was achieved by $61 \%$ and $40 \%$ of study participants treated with linagliptin and metformin or linagliptin groups after 24 weeks, respectively. Few patients experienced drug-related adverse events $(8.8 \%$ and $5.7 \%$ of patients in the linagliptin/metformin and linagliptin groups, respectively). Hypoglycemia without severe episodes occurred in $1.9 \%$ and $3.2 \%$ of patients in the linagliptin/metformin combination arm and linagliptintreated arm, respectively. Body weight decreased significantly with the combination therapy $(-1.3 \mathrm{~kg}$ between-group difference; $P=0.0033$ ). An initial combination of linagliptin and another oral antidiabetic agent (excluding a sulfonylurea) appears to provide a useful treatment option in patients whose blood glucose levels are increased to an extent that metformin monotherapy may not achieve therapeutic goals. Here, the use of a fixed dose combination tablet has the potential to reduce pill burden and simplify patients' treatment regimens, thereby promoting improved adherence and efficacy. ${ }^{33-35}$

\section{Linagliptin therapy in patients with renal impairment and CKD}

Linagliptin is the only DPP-4 inhibitor currently approved besides teneligliptin (that is currently approved in Japan and in South Korea) with a nonrenal elimination. ${ }^{21,36,37}$ A dose adjustment of linagliptin and teneligliptin in patients with 
CKD is not necessary since $>90 \%$ of the drug are excreted by a hepatobiliary route via the feces and both compounds can also be given in patients on dialysis. ${ }^{38-40}$ So far no direct headto-head studies between linagliptin and teneligliptin have been performed. For the other approved DPP-4 inhibitors, saxagliptin, siatgliptin, and vildagliptin dose adjustments are necessary in patients with a creatinine clearance $<50 \mathrm{~mL} / \mathrm{min}$, and there are restrictions for patients with end-stage renal disease in a dialysis program (Table 1). ${ }^{1,18,29,41,42}$

Efficacy, tolerability, and safety of linagliptin in combination with an antidiabetic background therapy were investigated in patients with type 2 diabetes and progressed CKD in a 1-year study. ${ }^{43}$ Patients with an eGFR $<30 \mathrm{~mL} / \mathrm{min} / 1.73 \mathrm{~m}^{2}$ and a baseline $\mathrm{HbA}_{1 \mathrm{c}}$ between $7.0 \%$ and $10.0 \%$ received 5 $\mathrm{mg}$ linagliptin or placebo as add-on. For efficacy, $\mathrm{HbA}_{1 \mathrm{c}}$ at week 12 was defined as an endpoint. Safety endpoints were determined at the end of the study after linagliptin led to an $\mathrm{HbA}_{1 \mathrm{c}}$ reduction of $-0.76 \%$ after 12 weeks. This reduction of $\mathrm{HbA}_{1 \mathrm{c}}$ was sustained for the whole study period of 52 weeks $(-0.71 \%$ for linagliptin vs $-0.01 \%$ for placebo, $P<0.0001)$. The patients, who had received insulin already in their baseline therapy, were able to lower the insulin doses by -6.2 units when treated with linagliptin and by -0.3 units when treated with placebo. Adverse events, including hypoglycemia, occurred in a comparable frequency $(94.1 \%$ for linagliptin vs $92.3 \%$ for placebo). The change in renal function and the incidence of cardiovascular events were also similar and fairly stable in both groups (median change in eGFR, $-0.8 \mathrm{vs}-2.2 \mathrm{~mL} / \mathrm{min} / 1.73 \mathrm{~m}){ }^{2,43}$

These study results are comparable to previous 24-week studies with similar $\mathrm{HbA}_{1 \mathrm{c}}$ reductions between $0.5 \%$ and $0.9 \%$ in patients with type 2 diabetes and normal or impaired renal function. . $^{27-29,43,44}$
Studies with saxagliptin, sitagliptin, and vildagliptin are difficult to compare since patient populations and study designs were different in the studies with these DPP-4 inhibitors. ${ }^{43}$ Direct comparative studies of the DPP-4 inhibitors are not available at present. The observed efficacies of linagliptin in lowering $\mathrm{HbA}_{1 \mathrm{c}}$ in patients with $\mathrm{CKD}$ were similar or greater compared to the efficacies of the other DPP-4 inhibitors in indirect comparisons. ${ }^{41,42,45}$ A recent observational study reported that sitagliptin was often dosed inappropriately in CKD with only $15 \%$ of patients with moderate or end-stage renal impairment being on an appropriate dose. ${ }^{46}$ Postprandial glucose reductions contribute to the glycemic improvement observed with linagliptin. ${ }^{27,29,47}$ In progressive and CKD and cardiovascular diseases, glycemic control cannot often be reached easily without adverse effects and an increased hypoglycemia risk. This phenomenon may be explained by a reduced renal gluconeogenesis and a decreased renal clearance of insulin and other antidiabetic agents. ${ }^{48}$

A recently published trial investigated the efficacy and safety of linagliptin in type 2 diabetic patients with moderateto-severe CKD and unsatisfactory glucose control. ${ }^{49}$ The study consisted of a 12-week, placebo-controlled treatment phase with a 40-week extension following right after with glimepiride $1-4 \mathrm{mg}$ /day as comparator to linagliptin in a double-blind, double-dummy design. The glimepiride dose could be uptitrated by $1 \mathrm{mg} /$ day in 4-week intervals to a dose of maximally $4 \mathrm{mg}$ /day if the fasting glucose exceeded $110 \mathrm{mg}$. The most important inclusion criteria were a baseline $\mathrm{HbA}_{1 \mathrm{c}}$ in the range from $7.0 \%$ to $10.0 \%$ and an eGFR $<60 \mathrm{~mL} /$ $\mathrm{min} / 1.73 \mathrm{~m}^{2}$. Altogether 235 patients were randomized $1: 1$ to placebo or linagliptin. Both groups were similar concerning their baseline characteristics. The important characteristics were an age of 66.6 years (mean) and $\mathrm{HbA}_{1 \mathrm{c}}$ of $8.1 \%$ at the

Table I Commonly used oral antidiabetic agents and their possible use in several stages of renal impairment

\begin{tabular}{|c|c|c|c|}
\hline & \multicolumn{3}{|l|}{ Creatinine clearance $(\mathrm{mL} / \mathrm{min})$} \\
\hline & $30-49$ & $15-29$ & $<\mid 5$ (dialysis) \\
\hline Metformin & - & - & - \\
\hline Sulfonylureas & Often dose reduction necessary & - & - \\
\hline SGLT-2 inhibitors & Loss of efficacy with lower eGFR & - & - \\
\hline Repaglinide & & & Use with caution \\
\hline Nateglinide & & Dose reduction & \\
\hline$\alpha$-glucosidase inhibitors & & $<25 \mathrm{~mL} /$ min contraindicated & - \\
\hline Pioglitazone & & $<4 \mathrm{~mL} / \mathrm{min}$ contraindicated & \\
\hline Sitagliptin (dose) & $\mathrm{I} \times 50 \mathrm{mg} /$ day & $\mathrm{I} \times 25 \mathrm{mg} /$ day & $\mathrm{I} \times 25 \mathrm{mg} /$ day \\
\hline Vildagliptin (dose) & $\mathrm{I} \times 50 \mathrm{mg} /$ day & $\mathrm{I} \times 50 \mathrm{mg} /$ day & I $\times 50 \mathrm{mg} /$ day dialysis: with caution \\
\hline Saxagliptin (dose) & $\mathrm{I} \times 2.5 \mathrm{mg} /$ day & $1 \times 2.5 \mathrm{mg} /$ day with caution & Not recommended \\
\hline Linagliptin (dose) & $1 \times 5 \mathrm{mg} /$ day & $\mathrm{I} \times 5 \mathrm{mg} /$ day & $1 \times 5 \mathrm{mg} /$ day \\
\hline
\end{tabular}

Abbreviations: eGFR, estimated glomerular filtration rate; SGLT-2, sodium-glucose-transporter-2. 
time of inclusion into the study, and the mean eGFR was 37.2 $\mathrm{mL} / \mathrm{min} / 1.73 \mathrm{~m}^{2}$. A total of $86 \%$ of the patients already had an insulin therapy. After 12 weeks, the $\mathrm{HbA}_{1 \mathrm{c}}$ was reduced by $-0.53 \%$ with linagliptin and by $-0.11 \%$ with placebo. After 52 weeks in the extension, the changes from baseline in $\mathrm{HbA}_{1 \mathrm{c}}$ were $-0.64 \%$ for linagliptin- and $-0.50 \%$ for placeboor glimepiride-treated patients. Drug-related adverse events occurred with similarly low incidence in both study arms in less than $25 \%$ of the patients. A smaller number of patients on linagliptin reported adverse events compared to glimepiridetreated patients $(90.7 \%$ vs $96.5 \%)$. In line with this finding, less patients on linagliptin experienced serious adverse events ( $22.4 \%$ on linagliptin vs $26.3 \%$ on glimepiride), and the incidence of adverse events leading to a premature study end was also lower in the linagliptin arm compared to the glimepiride $\operatorname{arm}(4.7 \%$ for linagliptin vs $9.6 \%$ for glimepiride). The incidence for cardiovascular events was lower in the linagliptin arm $(n=3)$ compared to the glimepiride study arm $(n=8)$. Expectedly, the hypoglycemia incidence was significantly lower in linagliptin-treated patients compared to glimepiride-treated patients throughout the whole study. The incidence of severe hypoglycemia was equal in both groups $(n=6)$. The eGFR did not change during the complete study in both groups. ${ }^{49,50}$

In this 1-year study, linagliptin was efficacious on glycemic parameters and tolerated well in the type 2 diabetic patients with moderate or severe CKD. Apart from that, the renal function did not change or worsen during the study. The results suggest that glycemic parameters can be significantly improved with linagliptin with an acceptable therapeutic side-effect profile in this population that only has limited treatment options due to the impaired renal function. Avoidance of hypoglycemia in these patients is a foremost treatment goal and more important than reaching low glucose values or a low $\mathrm{HbA}_{1 \mathrm{c}}$. Due to the high number of patients treated with insulin already, the hypoglycemia incidence was expectedly relatively high in both groups. The incidence was nevertheless lower in patients in the linagliptin arm compared with glimepiride therapy. Earlier studies comparing DPP-4 inhibitors and sulfonylureas have also demonstrated similar glucose-lowering efficacy of both drug classes but fewer adverse events associated with DPP-4 inhibitor use in patients with renal impairment. ${ }^{49-53}$

\section{Conclusion, final considerations, and future perspectives}

In order to prevent micro- and macrovascular diabetesassociated complications, good glycemic control is very important in treating type 2 diabetes. The association between hyperglycemia and the progression of these complications has been shown for type 2 diabetes in the late 1990's.,54,55 Therapeutic options to improve glycemia are however limited for patients with type 2 diabetes and vascular complications because many compounds are eliminated via a renal route. Under conditions of moderate or severe renal impairment, most of these treatment options are or contraindicated or not recommended (eg, metformin, $\alpha$-glucosidase inhibitors, SGLT-2 inhibitors, and many sulfonylureas, predominantly first-generation sulfonylureas). Some substance groups and compounds can only be used in significantly lower doses (eg, second-generation sulfonylureas, glinides, and most DPP-4 inhibitors). ${ }^{56,57}$ Pioglitazone, the only remaining thiazolidinedione that can be given in conditions of renal impairment, is no longer available in every country. ${ }^{58}$

The above mentioned studies with linagliptin in renally impaired patients support the use of this DPP-4 inhibitor without dose adjustments as a therapeutic alternative in these patients. The renal function therefore does not have to be monitored solely for the sake of putative dose calculations for the antidiabetic therapy. ${ }^{25,43,49}$ Table 1 illustrates the indications and contraindications for antidiabetic medications in relation to the kidney function. Furthermore, the renal function remained stable with the linagliptin therapy. If patients were on an insulin treatment before the addition of linagliptin, the insulin doses could be reduced.

DPP-4 inhibitor therapy has been shown to be cost effective as a second-line treatment when the glycemic goals are not met with metformin alone, especially in comparison to an add-on therapy with a sulfonylurea or a thiazolidinedione. ${ }^{59}$ Large and comprehensive cost-effective analyses on linagliptin are still incomplete, but the sitagliptin data can be used in analogy for linagliptin since DPP-4 inhibitors in general have a very low hypoglycemia risk and have shown a good therapeutic efficacy and adherence. Linagliptin may even produce more favorable data in this respect, considering the fact that it can be given with a standard dose throughout all stages of kidney function. Additional physician visits and laboratory controls for monitoring renal function for the sake of medication dose adjustments are not necessary. The therapy with linagliptin can be started early in type 2 diabetes when metformin monotherapy is not sufficiently effective and can be maintained without change during the whole disease progression.

Further studies with linagliptin and comparators of other antidiabetic drug classes are presently being carried out in patient cohorts with a high micro- and macrovascular risk. ${ }^{25,43}$ These studies will generate data on the long-term efficacy, durability, and safety of linagliptin with a special focus on 
vascular safety. The large ongoing vascular safety trials CAROLINA and CARMELINA will be completed before the end of this decade. Important answers concerning the value of DPP-4 inhibitors for type 2 diabetes treatment in general and about linagliptin in particular in a patient population with vascular risk factors will be covered by these two studies. ${ }^{25,60}$

\section{Disclosure}

The author is a member of advisory boards for AstraZeneca, Bristol-Myers Squibb, Boehringer Ingelheim (manufacturer of linagliptin), Eli Lilly, Novartis, Novo Nordisk, Merck, Roche, Sanofi-Aventis, and Takeda. He has also received honoraria from these companies for giving lectures.

\section{References}

1. National Kidney Foundation. KDOQI clinical practice guideline for diabetes and CKD: 2012 update. Am J Kidney Dis. 2012;60:850-886.

2. UK Prospective Diabetes Study (UKPDS) Group. Intensive bloodglucose control with sulphonylureas or insulin compared with conventional treatment and risk of complications in patients with type 2 diabetes (UKPDS 33). Lancet. 1998;352:837-853.

3. Stratton IM, Adler AI, Neil HA, et al. Association of glycaemia with macrovascular and microvascular complications of type 2 diabetes (UKPDS 35): prospective observational study. BMJ. 2000; 321(7258):405-412.

4. National Institute for Health and Care Excellence (NICE). Guidance. Type 2 diabetes: The management of type 2 diabetes. NICE guidelines [CG87]. Available from: http://www.nice.org.uk/guidance/cg87/ chapter/guidance. Accessed March 25, 2015.

5. Scheen AJ. Pharmacokinetic considerations for the treatment of diabetes in patients with chronic kidney disease. Expert Opin Drug Metab Toxicol. 2013;9(5):529-550.

6. Deacon C, Hughes T, Holst JJ. Dipeptidyl peptidase IV inhibition potentiates the insulinotropic effect of glucagon-like peptide 1 in the anesthetized pig. Diabetes. 1998;47:764-769.

7. Mentlein R, Gallwitz B, Schmidt W. Dipeptidyl-peptidase IV hydrolyses gastric inhibitory polypeptide, glucagon-like peptide-1(7-36)amide, peptide histidine methionine and is responsible for their degradation in human serum. Eur J Biochem. 1993;214:829-835.

8. Drucker D, Nauck M. The incretin system: glucagon-like peptide-1 receptor agonists and dipeptidyl peptidase-4 inhibitors in type 2 diabetes. Lancet. 2006;368:1696-1705.

9. Nauck MA, Kleine N, Orskov C, Holst JJ, Willms B, Creutzfeldt W. Normalization of fasting hyperglycaemia by exogenous glucagon-like peptide 1 (7-36 amide) in type 2 (non-insulin-dependent) diabetic patients. Diabetologia. 1993;36(8):741-744.

10. Stein SA, Lamos EM, Davis SN. A review of the efficacy and safety of oral antidiabetic drugs. Expert Opin Drug Saf. 2013;12(2): 153-175.

11. Seck T, Nauck M, Sheng D, et al; Sitagliptin Study 024 Group. Safety and efficacy of treatment with sitagliptin or glipizide in patients with type 2 diabetes inadequately controlled on metformin: a 2-year study. Int J Clin Pract. 2010;64(5):562-176.

12. Matthews DR, Dejager S, Ahren B, et al. Vildagliptin add-on to metformin produces similar efficacy and reduced hypoglycaemic risk compared with glimepiride, with no weight gain: results from a 2-year study. Diabetes Obes Metab. 2010;12(9):780-789.

13. Göke B, Gallwitz B, Eriksson JG, Hellqvist Å, Gause-Nilsson I. Saxagliptin vs glipizide as add-on therapy in patients with type 2 diabetes mellitus inadequately controlled on metformin alone: long-term (52-week) extension of a 52-week randomised controlled trial. Int $J$ Clin Pract. 2013;67(4):307-316.
14. Gallwitz B, Rosenstock J, Rauch T, et al. 2-year efficacy and safety of linagliptin compared with glimepiride in patients with type 2 diabetes inadequately controlled on metformin: a randomised, double-blind, non-inferiority trial. Lancet. 2012;380(9840):475-483.

15. Inzucchi SE, Bergenstal RM, Buse JB, et al. Management of hyperglycaemia in type 2 diabetes, 2015: a patient-centred approach. Update to a Position Statement of the American Diabetes Association and the European Association for the Study of Diabetes. Diabetologia. 2015; 58(3):429-442.

16. Forst T, Pfützner A. Linagliptin, a dipeptidyl peptidase- 4 inhibitor with a unique pharmacological profile, and efficacy in a broad range of patients with type 2 diabetes. Expert Opin Pharmacother. 2012;13(1):101-110.

17. Thomas L, Eckhardt M, Langkopf E, Tadayyon M, Himmelsbach F, Mark M. (R)-8-(3-amino-piperidin-1-yl)-7-but-2-ynyl-3-methyl-1(4-methyl-quinazolin-2-ylm ethyl)-3,7-dihydro-purine-2,6-dione (BI 1356), a novel xanthine-based dipeptidyl peptidase 4 inhibitor, has a superior potency and longer duration of action compared with other dipeptidyl peptidase-4 inhibitors. J Pharmacol Exp Ther. 2008;325: 175-182.

18. Eckhardt M, Hauel N, Himmelsbach F, et al. 3,5-Dihydroimidazo[4,5-d] pyridazin-4-ones: a class of potent DPP-4 inhibitors. Bioorg Med Chem Lett. 2008;18:3158-3162.

19. Gallwitz B. Small molecule dipeptidylpeptidase IV inhibitors under investigation for diabetes mellitus therapy. Expert Opin Investig Drugs. 2011;20:723-732.

20. Fuchs H, Tillement J, Urien S, Greischel A, Roth W. Concentrationdependent plasma protein binding of the novel dipeptidyl peptidase 4 inhibitor BI 1356 due to saturable binding to its target in plasma of mice, rats and humans. J Pharm Pharmacol. 2009;61:55-62.

21. Heise T, Graefe-Mody E, Huttner S, Ring A, Trommeshauser D, Dugi K. Pharmacokinetics, pharmacodynamics and tolerability of multiple oral doses of linagliptin, a dipeptidyl peptidase-4 inhibitor in male type 2 diabetes patients. Diabetes Obes Metab. 2009;11:786-794.

22. Graefe-Mody E, Jungnik A, Ring A, Woerle H, Dugi K. Evaluation of the pharmacokinetic interaction between the dipeptidyl peptidase-4 inhibitor linagliptin and pioglitazone in healthy volunteers. Int J Clin Pharmacol Ther. 2010;48:652-661.

23. Huttner S, Graefe-Mody E, Withopf B, Ring A, Dugi K. Safety, tolerability, pharmacokinetics and pharmacodynamics of single oral doses of BI 1356, an inhibitor of dipeptidyl peptidase 4, in healthy male volunteers. J Clin Pharmacol. 2008;48:1171-1178.

24. Friedrich C, Emser A, Woerle HJ, Graefe-Mody U. Renal impairment has no clinically relevant effect on the long-term exposure of linagliptin in patients with type 2 diabetes. Am J Ther. 2013;20(6):618-621.

25. Gallwitz B. Safety and efficacy of linagliptin in type 2 diabetes patients with common renal and cardiovascular risk factors. Ther Adv Endocrinol Metab. 2013;4(3):95-105.

26. Friedrich C, Ring A, Brand T, Sennewald R, Graefe-Mody EU, Woerle HJ. Evaluation of the pharmacokinetic interaction after multiple oral doses of linagliptin and digoxin in healthy volunteers. Eur J Drug Metab Pharmacokinet. 2011;36:17-24.

27. Del Prato S, Barnett AH, Huisman H, Neubacher D, Woerle HJ, Dugi KA. Effect of linagliptin monotherapy on glycaemic control and markers of beta-cell function in patients with inadequately controlled type 2 diabetes: a randomized controlled trial. Diabetes Obes Metab. 2011;13:258-267.

28. Kawamori R, Inagaki N, Araki E, et al. Linagliptin monotherapy provides superior glycaemic control versus placebo or voglibose with comparable safety in Japanese patients with type 2 diabetes: a randomized, placebo and active comparator-controlled, double-blind study. Diabetes Obes Metab. 2012;14(4):348-357.

29. Taskinen MR, Rosenstock J, Tamminen I, et al. Safety and efficacy of linagliptin as add-on therapy to metformin in patients with type 2 diabetes: a randomized, double-blind, placebo-controlled study. Diabetes Obes Metab. 2011;13:65-74.

30. Owens DR, Swallow R, Dugi KA, Woerle HJ. Efficacy and safety of linagliptin in persons with type 2 diabetes inadequately controlled by a combination of metformin and sulphonylurea: a 24-week randomized study. Diabet Med. 2011;28:1352-1361. 
31. Gallwitz B, Rosenstock J, Patel S, et al. Regardless of the degree of glycaemic control, linagliptin has lower hypoglycaemia risk than all doses of glimepiride, at all time points, over the course of a 2-year trial. Diabetes Obes Metab. 2015;17(3):276-284.

32. Gallwitz B, Rosenstock J, Emser A, von Eynatten M, Woerle HJ. Linagliptin is more effective than glimepiride at achieving a composite outcome of target $\mathrm{HbA}_{1 \mathrm{c}}$ \&lt; 7\% with no hypoglycaemia and no weight gain over 2 years. Int J Clin Pract. 2013;67(4):317-321.

33. Haak T, Meinicke T, Jones R, Weber S, von Eynatten M, Woerle HJ. Initial combination of linagliptin and metformin in patients with type 2 diabetes: efficacy and safety in a randomised, double-blind 1-year extension study. Int J Clin Pract. 2013;67(12):1283-1293.

34. Haak T. Combination of linagliptin and metformin for the treatment of patients with type 2 diabetes. Clin Med Insights Endocrinol Diabetes. 2015;8:1-6.

35. Ross SA, Caballero AE, Del Prato S, et al. Initial combination of linagliptin and metformin compared with linagliptin monotherapy in patients with newly diagnosed type 2 diabetes and marked hyperglycaemia: a randomized, double-blind, active-controlled, parallel group, multinational clinical trial. Diabetes Obes Metab. 2015;17(2):136-144.

36. Blech S, Ludwig-Schwellinger E, Grafe-Mody E, Withopf B, Wagner K. The metabolism and disposition of the oral dipeptidyl peptidase-4 inhibitor, linagliptin, in humans. Drug Metab Dispos. 2010;38:667-678.

37. Morishita R, Nakagami H. Teneligliptin: expectations for its pleiotropic action. Expert Opin Pharmacother. 2015;16(3):417-426.

38. Deacon C, Holst J. Linagliptin, a xanthine-based dipeptidyl peptidase-4 inhibitor with an unusual profile for the treatment of type 2 diabetes. Expert Opin Investig Drugs. 2010;19:133-140.

39. Graefe-Mody U, Friedrich C, Port A, et al. Effect of renal impairment on the pharmacokinetics of the dipeptidyl peptidase-4 inhibitor linagliptin. Diabetes Obes Metab. 2011;13:939-946.

40. Otsuki H, Kosaka T, Nakamura K, Shimomura F, Kuwahara Y, Tsukamoto T. Safety and efficacy of teneligliptin: a novel DPP-4 inhibitor for hemodialysis patients with type 2 diabetes. Int Urol Nephrol. 2014;46(2):427-432.

41. Kothny W, Shao Q, Groop P, Lukashevich V. One-year safety, tolerability and efficacy of vildagliptin in patients with type 2 diabetes and moderate or severe renal impairment. Diabetes Obes Metab. 2012;14:1032-1039.

42. Nowicki M, Rychlik I, Haller H, et al. Long-term treatment with the dipeptidyl peptidase- 4 inhibitor saxagliptin in patients with type 2 diabetes mellitus and renal impairment: a randomised controlled 52-week efficacy and safety study. Int J Clin Pract. 2011;65:1230-1239.

43. McGill J, Sloan L, Newman J, et al. Long-term efficacy and safety of linagliptin in patients with type 2 diabetes and severe renal impairment: a 1-year, randomized, double-blind, placebo-controlled study. Diabetes Care. 2013;36:237-244.

44. Gomis R, Espadero R, Jones R, Woerle H, Dugi K. Efficacy and safety of initial combination therapy with linagliptin and pioglitazone in patients with inadequately controlled type 2 diabetes: a randomized, double-blind, placebo-controlled study. Diabetes Obes Metab. 2011;13:653-661.

45. Nowicki M, Rychlik I, Haller H, Warren M, Suchower L, Gause-Nilsson I. Saxagliptin improves glycaemic control and is well tolerated in patients with type 2 diabetes mellitus and renal impairment. Diabetes Obes Metab. 2011;13:523-532.
46. Meyers J, Candrilli S, Kovacs B. Type 2 diabetes mellitus and renal impairment in a large outpatient electronic medical records database: rates of diagnosis and antihyperglycemic medication dose adjustment. Postgrad Med. 2011;123:133-143.

47. Monnier L, Lapinski H, Colette C. Contributions of fasting and postprandial plasma glucose increments to the overall diurnal hyperglycemia of type 2 diabetic patients: variations with increasing levels of $\operatorname{HbA}\left({ }_{1 c}\right)$. Diabetes Care. 2003;26:881-885.

48. Ritz E. Limitations and future treatment options in type 2 diabetes with renal impairment. Diabetes Care. 2011;34(Suppl 2):S330-S334.

49. Laakso M, Rosenstock J, Groop PH, et al. Treatment with the dipeptidyl peptidase-4 inhibitor linagliptin or placebo followed by glimepiride in patients with type 2 diabetes with moderate to severe renal impairment: a 52-week, randomized, double-blind clinical trial. Diabetes Care. 2015 38(2): e15-e17.

50. Boehringer Ingelheim BI Trial Nr. 1218.64 1. - 15. CTR Main Part. Available from: http://trials.boehringer-ingelheim.com/content/dam/ internet/opu/clinicaltrial/com EN/results/1218/1218.64_U13-128301-DS.pdf. Accessed March 25, 2015.

51. Arjona Ferreira JC, Corry D, Mogensen CE, et al. Efficacy and safety of sitagliptin in patients with type 2 diabetes and ESRD receiving dialysis: a 54-week randomized trial. Am J Kidney Dis. 2013;61(4):579-587.

52. Arjona Ferreira JC, Marre M, Barzilai N, et al. Efficacy and safety of sitagliptin versus glipizide in patients with type 2 diabetes and moderateto-severe chronic renal insufficiency. Diabetes Care. 2013;36(5): 1067-1073.

53. Chan JC, Scott R, Arjona Ferreira JC, et al. Safety and efficacy of sitagliptin in patients with type 2 diabetes and chronic renal insufficiency. Diabetes Obes Metab. 2008;10:545-555.

54. UK Prospective Diabetes Study (UKPDS) Group. Effect of intensive blood-glucose control with metformin on complications in overweight patients with type 2 diabetes (UKPDS 34). Lancet. 1998;352: 854-865.

55. Ohkubo Y, Kishikawa H, Araki E, et al. Intensive insulin therapy prevents the progression of diabetic microvascular complications in Japanese patients with non-insulin-dependent diabetes mellitus: a randomized prospective 6-year study. Diabetes Res Clin Pract. 1995;28: 103-117.

56. Bakris G. Recognition, pathogenesis and treatment of different stages of nephropathy in patients with type 2 diabetes mellitus. Mayo Clin Proc. 2011;86:444-456.

57. Shrishrimal K, Hart P, Michota F. Managing diabetes in hemodialysis patients: observations and recommendations. Cleveland Clin J Med. 2009;76:649-655.

58. Chapelsky M, Thompson-Culkin K, Miller A, Sack M, Blum R, Freed M. Pharmacokinetics of rosiglitazone in patients with varying degrees of renal insufficiency. J Clin Pharmacol. 2003;43:252-259.

59. Schwarz B, Gouveia M, Chen J, et al. Cost-effectiveness of sitagliptinbased treatment regimens in European patients with type 2 diabetes and haemoglobin $\mathrm{A}_{1 \mathrm{c}}$ above target on metformin monotherapy. Diabetes Obes Metab. 2008;10(Suppl 1):43-55.

60. Marx N, Rosenstock J, Kahn SE, et al. Design and baseline characteristics of the CARdiovascular Outcome Trial of LINAgliptin Versus Glimepiride in Type 2 Diabetes (CAROLINA $\left.{ }^{\circledR}\right)$. Diab Vasc Dis Res. 2015;12(3):164-174.
Therapeutics and Clinical Risk Management

\section{Publish your work in this journal}

Therapeutics and Clinical Risk Management is an international, peerreviewed journal of clinical therapeutics and risk management, focusing on concise rapid reporting of clinical studies in all therapeutic areas outcomes, safety, and programs for the effective, safe, and sustained use of medicines. This journal is indexed on PubMed Central, CAS,

\section{Dovepress}

EMBase, Scopus and the Elsevier Bibliographic databases. The manuscript management system is completely online and includes a very quick and fair peer-review system, which is all easy to use. Visit http://www.dovepress.com/testimonials.php to read real quotes from published authors. 